\title{
Chapter 9 \\ Exploring Teachers' Values and Valuing Process in School-Based Lesson Study: A Brunei Darussalam Case Study
}

\author{
Nor Azura Abdullah and Frederick Koon Shing Leung
}

\begin{abstract}
In recent years, there is an interest of studies emphasising on the importance of values in mathematics education (Bishop 1999; Macnab 2000; Pa 2009). This study focuses on teachers' values and valuing process within the context of lesson study in school settings. By aligning the lesson study process with Raths et al. (1987) valuing process framework and Bishop's framework of mathematical values of teachers (1988), this study provides a platform for the valuing process to emerge, and this may help to articulate teachers' values in mathematics teaching. This study found that the lesson study processes enabled the value indicators to be observed and studied at three different levels in the curriculum, namely; intended, implemented and attained. By studying the value indicators closely, it was discovered that the teachers' values may get affected by the bilingual context in the mathematics classroom of Brunei, which were also affecting teachers' instructional practices.
\end{abstract}

Keywords Fractions $\cdot$ Lesson study $\cdot$ Mathematical values $\cdot$ Valuing

\subsection{Introduction}

Researching values in mathematics and mathematics education has increased in recent years. Bishop (2008) proposed that to study the intention behind teachers' classroom practices is perhaps to study them from a values perspective. Bishop suggests this to be done from a socio-cultural perspective, particularly at the pedagogical and individual levels (Bishop 1988). Understanding teachers' values in teaching mathematics is not a straightforward process, especially in terms of their development. However, Lim and Kor (2012) see values, which could be espoused and/or enacted, to have a role in affecting teachers' instructional practices. Other

\author{
N. A. Abdullah $(\varangle)$ \\ Faculty of Education, The University of Hong Kong, Pokfulam, Hong Kong SAR, China \\ e-mail: azura.abdullah@ubd.edu.bn \\ F. K. S. Leung \\ The University of Hong Kong, Pokfulam, Hong Kong SAR, China \\ e-mail: frederickleung@hku.hk


researchers (Bishop 2007; Kadroon and Inprasitha 2013) believe that lesson study is a suitable way to study the teachers' values development in the classroom. Since the main highlight of the lesson study process is the collaborative work between teachers, perhaps through this active collaborative interaction, teachers' values can be made more obvious (Bishop and Seah 2008).

Brunei Darussalam has reformed its education system and nation-wide curriculum since 2009. It was introduced as Sistem Pendidikan Negara abad 21 (also known as SPN21) or its English equivalent: National Education System for the 21st Century. The reformed mathematics curriculum puts emphasis on higher order mathematical thinking, holistic understanding of mathematical concepts and processes, and inquiry-oriented mathematics learning. In addition, the curriculum also puts stress on the students' mathematics skills on communicating their understanding, relating learned mathematics to real life problems and positive affective attitude to mathematics (Curriculum Development Department [CDD] 2010). This warrants for continuous professional development programs for school leaders and teachers to understand the reforms' objectives and contents. Among these programs, the Ministry of Education adopted a professional development approach originally from Japan called lesson study, specifically for the nation's centralized mathematics curriculum, which Stigler and Hiebert (1999) argued often helped in implementing reform ideas.

Lesson study is a teacher-initiated professional development approach set up in school and classroom settings. Stigler and Hiebert (1999) noted that the lesson study approach consisted of several successive actions plans. The first stage is for the teachers to investigate the lesson problem, plan the lesson, conduct the lesson, evaluate the lesson and reflect on it. The second stage is for the teachers to revise the lesson, conduct the revised lesson, evaluate the revised lesson and share the results. The pinnacle of lesson study is the collaborative work among teachers, and if needs be, outsiders, in conducting these action plans. Specifically, it is through the lesson study processes that "create changes in teachers' knowledge and beliefs, professional community, and teaching-learning resources" (Lewis et al. 2009, p. 286). It was anticipated that lesson study could help to remedy the gap between Brunei teachers' interpretation of the reform syllabus and their instructional practices in the classroom (Department of Planning, Development and Research [DPDR] 2014).

However, the transferability and adaptation of lesson study outside Japan have not always been successful. Fujii (2014) states that the practices of lesson study are often different from how the Japanese counterparts practice it. He believes that "the consideration of educational values is always tied to, influenced by, and reflected in, the key features of lesson study" (p. 78) and this emphasis on values may not always be present in the adaptation process. Perhaps teachers' values are not highlighted when Japanese lesson study is practiced elsewhere. Therefore, it is important to study the values aspect of lesson study in order to have an effective adoption of teachers' professional development approach in Brunei.

In order to have a holistic picture of teachers' espoused values, it is imperative to study values from three different processes in mathematics education (Tomlinson and Quinton 1986; Lim and Ernest 1997; Law et al. 2012): aims or intended outcomes; means or teaching/learning processes; and effects or actual outcomes (Tomlinson and 
Quinton 1986, p. 3). Law et al. (2012) suggested these processes as pre-lesson, the observed lesson and post-lesson (p. 47). Meanwhile, Lim and Ernest (1997) suggested these processes in terms of levels in the curriculum, that is, the intended, implemented and attained curriculum (p. 37). In this study, values were explored from teachers' talk during lesson study processes of the planning stage (intended/aims), lesson teaching stage (implemented/means) and post-lesson meeting stage (attained/effects).

Raths et al. (1987) stated that people show signs of 'value indicators' when they go through a valuing process. They suggested that this process has seven stages of turning their beliefs into actions and cementing the final product as values. These stages include (1) choosing freely; (2) choosing from alternatives; (3) choosing after thoughtful consideration of the consequences of each alternative; (4) prizing and cherishing; (5) affirming; (6) acting upon choices; and (7) repeating (Raths et al. 1987, pp. 199-200). They go on to suggest that the seven stages can be further condensed into three main stages of choosing, prizing and acting, which are at the core of the process (p. 201). Therefore, it seems that these three core stages of the valuing process can be aligned with the lesson study process. Hereby, teachers' talk during planning sessions can be taken as value indicators at the choosing and prizing stages; teachers' talk during teaching sessions can be taken as value indicators at the affirming and acting stages; and teachers' talk during post-lesson discussion sessions can be value indicators at the repeating stage. Following Raths et al's framework, when value indicators have gone through all the stages above, only then the outcomes could be considered as values. In this study, teachers' values are being explored through their process of valuing in the lesson study processes of planning, teaching and post-lesson discussion.

\subsection{Methodology}

The research design is a case study using a qualitative approach (Yin 2003). This study attempted to study how teachers' values could be explored in the lesson study process by focusing on teachers' act of valuing their instructional practices. In this context, qualitative case study is useful in answering a "how" question "about a contemporary set of events over which a researcher has little or no control" (Yin 2003, p. 14). The study involved a school located in the capital of Brunei, Kelawar Primary School (pseudonym), that is considered as the pioneer of lesson study in mathematics due to its involvement at the early stage of a nation-wide lesson study project and teachers' familiarity with the lesson study approach. The lessons focused on were Year 4 mathematics lessons unit on addition and subtraction of fractions. There were six female mathematics teachers involved in the study with two teachers undertaking the actual teaching. One of the six teachers was only involved in the beginning of the study since she felt the need to remove herself from the lesson study due to her heavy commitment as she was also a Year 6 mathematics teacher.

The focus of the study was to explore the values and valuing process of a group of teachers involved in lesson study, especially the implementers, Teacher Melinda 
Table 9.1 Teachers' participation in lesson study (pseudonyms were used to identify the teachers)

\begin{tabular}{l|l|l|l|l|l|l|l|l}
\hline \multirow{2}{*}{ Teachers } & \multicolumn{2}{|l|}{ Planning discussion } & \multicolumn{2}{l|}{$\begin{array}{l}\text { Addition of } \\
\text { fractions lessons }\end{array}$} & \multicolumn{2}{l|}{$\begin{array}{l}\text { Subtraction of } \\
\text { fractions lessons }\end{array}$} & \multirow{2}{*}{$\begin{array}{l}\text { Post-lesson } \\
\text { discussion }\end{array}$} \\
\cline { 2 - 8 } & 1st & 2nd & Class A & Class C & Class A & Class C & \\
\hline Melinda & Yes & Yes & Yes** & Yes & Yes** & Yes & Yes \\
\hline Ida & Yes & Yes & No & Yes** & Yes & Yes** & Yes \\
\hline Athena & Yes & Yes & No & Yes & Yes & No & Yes \\
\hline Carol & Yes & No & No & No & No & No & Yes \\
\hline Rosanna & Yes & No & No & No & No & No & Yes \\
\hline Alice & Yes & Yes & No & No & No & No & No \\
\hline $\begin{array}{l}\text { HM (head- } \\
\text { mistress) }\end{array}$ & No & No & No & No & No & No & Yes \\
\hline
\end{tabular}

**Implementer

and Teacher Ida (pseudonyms were used to protect the identity of the teachers). The aim of the lesson study group was to develop and implement effective mathematics lessons on the unit "Fraction". Thus, the values explored in this study happened in natural settings and occurred without teachers specifically deliberating on the values.

The teachers were observed and video recorded during their planning discussion meetings, lesson implementation and post-lesson discussion meetings. Six teachers attended two planning discussion meetings (see Table 9.1). The teachers were a mix of lower and upper primary mathematics teachers. In the lesson planning sessions, two days' lessons on addition and subtraction of fractions were discussed. Four lessons, conducted in class $\mathrm{A}$ and $\mathrm{C}$, in total were implemented and one post-lesson discussion was undertaken (see Table 9.1).

The handbook prepared by Peter Dudley (2014) was used as the tool to help teachers understand the lesson study process. Teachers found the handbook very useful and did adapt the ideas when they saw a need to do so. The forms they used were the lesson observation forms that aided them to focus on students' learning based on the lessons they planned. They also used post-lesson discussion forms to give their feedback on the lessons based on their observation and hence assessed the effectiveness of the lessons they observed.

As mentioned above, this study employs Bishop's (1988) idea of the socio-cultural dimension at pedagogical and individual levels. At these levels, the focus is on the teachers' valuing process and values and the choices they make in mathematics classrooms. Specifically, there are three flag points at this level where teachers' value indicators were explored, namely at the intended, implemented and attained points. Since teachers' values were explored at different flag points, for the sake of clarity, teachers' value indicators explored at the planning stage are called intended value indicators; teachers' value indicators explored at the teaching stage are called implemented value indicators; and teachers' value indicators explored at the post-lesson discussion stage are called attained value indicators. The exploration of teachers' 
Table 9.2 Bishop's $(1988,2007)$ mathematical values and teacher's decisions on instructional practices

\begin{tabular}{l|l|l}
\hline Component & Values & Prompts \\
\hline Ideological & Rationalism & $\begin{array}{l}\text { Teacher encourages students to give explanations, arguments or } \\
\text { show mathematics proofs }\end{array}$ \\
\cline { 2 - 3 } & Objectism & $\begin{array}{l}\text { Teacher encourages students to show or use diagrams, or } \\
\text { concretising mathematics ideas }\end{array}$ \\
\hline Sentimental & Control & $\begin{array}{l}\text { Teacher encourages students to understand the process of routine } \\
\text { calculations or check their answers and justify them }\end{array}$ \\
\cline { 2 - 3 } & Progress & $\begin{array}{l}\text { Teacher encourages students to explore ideas beyond given } \\
\text { examples }\end{array}$ \\
\hline Sociological & Openness & $\begin{array}{l}\text { Teacher encourages students to present and defend their ideas } \\
\text { with whole class }\end{array}$ \\
\cline { 2 - 3 } & Mystery & $\begin{array}{l}\text { Teacher encourages students explore their imagination on the } \\
\text { wonder of mathematical ideas }\end{array}$ \\
\hline
\end{tabular}

values was done according to the "prompts" based on Bishop's (1988, 2007) categories as summarized in Table 9.2. All video recordings done at planning meeting, classroom teaching and post-lesson discussion stages were transcribed. Teachers' talk was studied to be value indicators of the prompts as shown in Table 9.2. Some of the talks were explicitly expressed showing clear indication of the prompts. For example, Melinda: “you are going to use this one (strip paper). It's either you fold or you draw the lines, the parts, and then you show me how you're going to get the answer". This is categorized as valuing objectism where the teacher encourages students to use concrete materials to show their mathematics ideas. However, some of the underlying values in teachers' talks were not clear and attempts were made to infer the prompts from excerpts of teachers' conversations or from teacher-students' interactions. For example, Ida: “Okay, why did I ask Albus to fold this into six?” Here the teacher used her questioning technique to seek possible reasons from students to Albus's answer. We inferred from this incident that Ida is encouraging her students to give explanations of the concept learned and this action seems to be valuing rationalism. More examples can be seen in the results and discussion section.

In chronological order from planning sessions, lessons implementations to postlesson discussion meetings, thematic analysis (Braun and Clarke 2012) was done on the transcripts. Based on Bishop's framework (Table 9.2), the teachers' talks were coded deductively according to the prompts they exhibited as value indicators to teaching fractions. At the same time, inductive thematic analysis was also used to describe the structural content of teachers' meetings and teachings. 


\subsection{Results and Discussion}

The results of this study are presented in three sections. Section 9.3.1 describes the value indicators of the group of teachers during their discussions in planning the lessons. Section 9.3.2 reports on the flow of the lessons implemented and value indicators that the implementers enacted during their teaching. Section 9.3.3 looks into the value indicators of the group of teachers during their post-lesson discussion.

\subsubsection{Intended Value Indicators in Planning Sessions}

According to Seah (2002), teachers reveal their values about mathematics and about the teaching of mathematics when they decide on the sequence and best strategies for teaching specific topics. Over two hours of recording was collected from the teachers' planning sessions in teaching a sub-unit of the topic fractions. The classes that they planned to teach were preceded by a few lessons on basic fractions before moving into the selected planned lessons of addition and subtraction of fractions. In these planning sessions, teachers' discussions seem to focus on three main themes: the structure of the lessons, the strategies of presenting the lessons, and the students' abilities to do the tasks set out for them. Teachers discussed the structure of the lesson in terms of recalling previous knowledge of fractions as introduction, developing anchor tasks and presenting the lesson development.

In the discussion on strategies to present the lesson, the teachers decided to present the topic using concrete materials and pictures or diagrams. The concrete materials they agreed on were coloured folding papers as bar models and pizza models. Teachers talked about students' abilities to 'see' the conversion of fraction and to correctly add two related fractions with the aid of diagrams and concrete materials. For the introduction problems and anchor tasks, teachers were planning on starting with simple problems as an introduction to addition of fractions and they decided to use diagrams first. They also voiced their concern on introducing the concepts abstractly in the first lesson, hence finalising their decision to use concrete materials in the lesson development followed by pictures or diagrams and then abstracts workings.

Later in the discussion on the lesson development, teachers were concerned with whether students are able to 'visualise' the process of getting equivalent fractions between related fractions of $1 / 2$ and $1 / 4$. The teachers opted to use concrete materials, in this case coloured paper. The teachers planned to scaffold the sequence of the lesson to get students to 'see' the process of adding two related fractions by converting the fractions to their equivalent fractions and then adding them.

Since the teachers decided to conduct activities using concrete materials or pictures/diagrams, we infer that they were valuing objectism in the teaching of fractions. In their discussions, teachers used textbooks and teachers' guide as their point of reference when deciding on problems for students' activities. In the textbooks, fractions charts and bar models were used to depict fractions computations and, in the syllabus, 
it was recommended to "use concrete fractions models and fraction charts to help pupils add and subtract related fractions" (Curriculum Development Department 2008, p. 35). Perhaps, this may explain teachers' inclination to encourage students to use concretes or diagrams.

\subsubsection{Implemented Value Indicators in Teaching Sessions}

Two teachers implemented the four lessons, teaching two consecutive lessons each. The lessons were on addition and subtraction of fractions, a sub-unit under the topic of fractions. The teachers taught the lessons according to their plans as discussed. All four lessons had a similar structure with few differences in the teachers' nuances in lesson delivery. The lessons were structured in four phases as follows.

- Starting the lessons with objectives.

- Recalling previous knowledge.

- Solving problems.

- Summarising the lesson.

\subsubsection{Lesson Objectives}

Both teachers Melinda and Ida started their lessons by telling students the objectives of the lesson. These introductions were straight forward and do not show any signs of valuing mystery. In Melinda's case, she specifically wrote on the board "we are learning to...", stating the lesson objectives, and asked students to recite the objectives before starting the lessons. This is consistent with her pre-lesson study interview where she stated, "my introduction is always reading the learning intention and discussing the success criteria. Because you have to share before you go through the lessons". Perhaps from the teachers' actions, it could be inferred that they are valuing control, more so in teacher Melinda's practice, because they have established the targeted outcome for students to focus on. The actions also show that the teachers valued openness as they share with the students the aim of the lesson directly at the opening of the lesson.

\subsubsection{Recalling Previous Knowledge}

Both Melinda and Ida recalled their students' previous knowledge in the lessons as their lesson introductions. Ida used words such as remember and recall to draw students' attention on what they have learnt. She would ask students how to solve a problem and reminded them on how they have done it previously. She then proceeded to show the correct working. Ida tried to get her students to recall previously learnt procedural skills, followed by her demonstration of the skills and then encouraged 
her students to show the working referring to her example. Meanwhile, Melinda recalled students' previous knowledge before giving them a problem. She asked them conceptual questions such as definitions of fractions and procedural questions on adding fractions. She encouraged her students to explain their answers. Here, it could be inferred that Ida's actions valuing objectism whereas Melinda valuing rationalism.

\subsubsection{Solving Problems}

As planned, the teachers explained the concepts through students' activity of solving problems. During this section of the lessons, both teachers encouraged their students to use concrete materials such as fraction base, round paper pizza and 'strip paper' to solve the problems. This shows that the teachers are valuing objectism when they supported their students to use these and indeed other objects as well to concretise the mathematics concepts.

At the same time, both teachers also encouraged their students to explain their method of working by discussing it with their peers in pairs, or as whole class interaction. However, during the students and teachers classroom conversations, the students tended to give one word answers. When this occurred the teachers would resort to the concrete materials or pictures to get the students to explain. In this scenario, both teachers showed their attempts at getting students to discuss and explain their work with each other. This seems to imply that both teachers valued rationalism but were hindered by students' communication skills.

Even with students lacking in communication skills, both teachers encouraged their students to present and share their work in front of the whole class. By encouraging students to present their ideas to their peers, the teachers showed signs of valuing openness. To help better communication of ideas, the teachers encouraged their students to use their drawings as an aid to help with their explanations. This implies that the teachers valued objectism. This could be because in the Bruneian context, mathematics is taught in English, which is the second or even third language for most students. Hence it may be difficult for students to articulate their thinking to others and a medium in the form of concrete objects or diagrams was needed to communicate. In addition to this, both teachers 'took over' the students' presentation to further explain the steps of their workings to check their answers and emphasised the lesson development to the class. This action may indicate teachers are valuing control. Hence in this section, both teachers were inferred to be valuing objectism, rationalism, control and openness. These similarities may be due to their discussion of presenting problems to the students during planning.

\subsubsection{Lesson Summary}

Both teachers summarized their teaching towards the end of their lessons. Ida summarised both her lessons by asking the whole class the steps of adding or subtracting 
fractions. She wrote the steps on the whiteboard while explaining. Melinda only recapped her second lesson verbally with the whole class briefly at the end of her lesson. Both teachers resorted to verbal summary of their lessons.

Seah (2002) explained that teachers' values influenced them to make conscious decisions on their instructional practices. Based on the video recordings and transcripts, both teachers showed major hints in their actions of valuing objectism from their practice of folding papers and diagrams; and to a certain degree rationalism, control and openness in teaching the lessons.

\subsubsection{Attained Value Indicators in the Post-lesson Session}

Two hours of discussion were held after school with five of the teachers, with the headmistress present. The teachers watched clips of the classroom videos, looked at students' worksheets, and used their own classroom observation notes during this discussion. With the presence of the headmistress, the teachers' intentions and choices of teaching strategies were discussed. These talks provided more insights into the teachers' valuing process as to why they have chosen the instructional practices. The headmistress explained that she inquired the reasonings behind the strategies used by the teachers to understand the mathematics lesson as well as acting her role as an appraiser, to learn the teachers' expertise. However, during the presence of the headmistress, the teachers shared only the students' work and misconceptions. Further discussion on their teaching was done after the headmistress had left. It seems that with the presence of the headmistress, the teachers put the focus of discussion on students and not on themselves. This is perhaps because their headmistress is also their performance's appraiser.

Teachers referred to the students' work activity, with the aid of using diagrams, to assess students' understanding of the topic. From students' diagrams, teachers found three misconceptions in fractions where students used, first, different shapes to denote the same fractions. Second, different sizes of fractional shapes were used to denote same fractions. And third, students drew wrong diagrams but reached the correct answer. In addition to advocating the use of diagrams to assess students' thinking, the teachers reiterated the importance of diagrams to help students to see the concepts learnt. Consistently, teachers are valuing objectism. However, when focusing on the teachings, teachers highlighted their preference for moving the transition from concrete/diagram to abstract quickly as this would save time for students to find solutions especially during examination periods. This may depict teachers to valuing control. 


\subsubsection{Summary}

Having a holistic picture of teachers' valuing process in the lesson study sessions provides insights into teachers' values. First, teachers' values could be explored from the value indicators in three different sessions of lesson study. This is especially true in Melinda's case, where she has shown to be valuing the importance of concretising the concepts of fractions and processes of adding and subtracting fractions. She consistently showed her persistence with the use of concrete objects and diagrams in her instructional practices during the planning discussions, her lesson presentations and the post-lesson discussions. We conclude that she valued objectism. However, we should take into consideration that these values may be dependent on the topic taught or the context of the lesson. In this case, the syllabus in Brunei recommended the use of concrete materials and diagrams in teaching fractions. It is important to note that in her lessons, she also attempted to get her students to explain to the whole class their ideas and justifying their answers. The responses were minimal, and Melinda encouraged her students to use concrete materials to aid their explanation. This could be due to the complex concept of fractions. Yusof and Malone (2003) found that fractions in Brunei primary schools is generally a difficult topic for students to learn. They concluded that this is due to two main reasons: lack of use of manipulatives in teachers' instructions of teaching fractions and lack of English proficiency from bilingual students. However, in this study, the teachers preferred to teach using concrete materials as they agreed to use a concrete-pictorial-abstract approach. Therefore, it could be the language difficulties that the students faced in expressing their ideas and thinking that impeded their communication skills. This might also be the reason why teachers showed an inclination towards valuing objectism more than rationalism.

Second, teachers' values could be understood further when the reasonings behind teachers' decisions of valuing a strategy or approach were examined. For example, teachers were valuing objectism by encouraging students to use concrete materials or diagrams for different purposes. In the planning sessions, the main reason is for students to 'see' the processes. In the teaching sessions, use of concrete materials or diagrams was to aid students in explaining their thoughts. In post-lesson discussions, it can be seen that teachers used students' drawings to assess their understanding of the lesson. Thus, as Fujii (2014) has stated, values could be reflected from and influenced by each of the lesson study processes. This is especially true in this case where values indicators reflecting objectism was consistently present at each process due to different reasons. In the planning sessions, objectism was valued to intend students to visualise the concepts; in the teaching sessions, objectism was valued to implement students' communication skills; and in the post-lesson discussions, objectism was valued to assess the attainment of the lessons. 


\subsection{Conclusion}

There are two observations that we can take from this study. First, from the lesson study processes, we were able to look at value indicators at pre-lesson, during the lesson and post-lesson stages. The teachers' talk at these stages highlighted the teachers' preferences as they decided, implemented and pondered on the instructional practices, which can be treated as value indicators. Thus, as Fujii (2014) has stated, in the lesson study setting, the processes play a significant role in underlining teachers' values and these values are important for the effectiveness of lesson study as professional development for teachers in the mathematical learning of their students. However, this study only looked at the lesson study processes for one unit of lesson in a single cycle where no revised lessons were observed, limiting on how teachers' values may influence changes in their following lessons.

Second, by focusing on teachers' value indicators, their talks throw light on the reasons behind their preferences. With reference to Melinda's case, she has shown a pull between her valuing rationalism and valuing objectism to get her students to communicate their mathematical thinking. Due to the difficulties between the language of instruction and the mother tongue in a bilingual situation, and the challenges that come with it in the teaching and learning of mathematics, this study illustrates how the context may affect teachers' values and preferences in deciding their instructional practices in mathematics lessons. Teachers' values of mathematics teaching and learning might be different due to the bilingual context in the mathematics classroom of Brunei. Bishop (2001) explained that the mathematical values he elaborated were based on Western mathematics and may differ for different cultures. Perhaps, this study could elucidate teachers' valuing process and values in a bilingual culture.

Acknowledgements Part of this paper was taken from the first author's unpublished PhD research proposal that was submitted to the University of Hong Kong.

\section{References}

Bishop, A. (1988). Mathematical enculturation: A cultural perspective on mathematics education. Dordrecht: Kluwer Academic Publishers.

Bishop, A. J. (1999). Mathematics teaching and values education: An intersection in need of research. ZDM Mathematics Education, 31(1), 1-4.

Bishop, A. J. (2001). What values do you teach when you teach mathematics? Teaching Children Mathematics, 7(6), 346-349.

Bishop, A. (2007). Teachers' mathematical values for developing mathematical thinking through lesson study. Processing of APEC-KHONKAEN International Symposium: Innovative Teaching Mathematics through Lesson Study (II)_Focusing on Mathematical Thinking. CRME, Khon Kaen University.

Bishop, A. (2008). Mathematics teaching and values education: An intersection in need of research. In P. Clarkson \& N. Presmeg (Eds.), Critical issues in mathematics education: Major contributions of Alan Bishop (pp. 231-239). New York: Springer. 
Bishop, A. J., \& Seah, W. T. (2008). Educating values: Possibilities and challenges through mathematics teaching. In M. H. Chau \& T. Kerry (Eds.), International perspectives on education (pp. 118-138). London: Continuum.

Braun, V., \& Clarke, V. (2012). Thematic analysis. In H. Cooper (Ed.), Handbook of research methods in psychology: Vol. 2. Research designs (pp. 57-71). Washington, DC: American Psychological Association.

Curriculum Development Department. (2008). SPN21 syllabus year 4. Brunei Darussalam: Ministry of Education.

Curriculum Development Department. (2010). Framework and guidelines for curriculum and assessment: Mathematics year 6. Brunei Darussalam: Ministry of Education.

Department of Planning, Development and Research. (2014). Teachers and the teaching of Bahasa Melayu, English and Mathematics in primary schools in Brunei Darussalam. Unpublished research report. Brunei Darussalam: Ministry of Education.

Dudley, P. (2014). Lesson study: A handbook. Retrieved from http://lessonstudy.co.uk/wp-content/ uploads/(2012)/03/Lesson_Study_Handbook_-_011011-1.pdf.

Fujii, T. (2014). Implementing Japanese lesson study in foreign countries: Misconceptions revealed. Mathematics Teacher Education and Development, 16(1), 65-83.

Kadroon, T., \& Inprasitha, M. (2013). Professional development of mathematics teachers with lesson study and open approach: The process for changing teachers values about teaching mathematics. Psychology, 4(2), 101-105.

Lewis, C., Perry, R., \& Hurd, J. (2009). Improving mathematics instructions through lesson study: A theoretical model and North American case. Journal of Mathematics Teacher Education, 12, 285-304.

Law, H. Y., Wong, N. Y., \& Lee, N. Y. L. (2012). A study of espoused values in Hong Kong's mathematics classrooms. ZDM - The International Journal on Mathematics Education, 44(1), $45-57$.

Lim, C. S., \& Ernest, P. (1997). Values in mathematics education: What is planned and what is espoused? Paper presented at the conference of the British Society for Research into Learning Mathematics, Nottingham, UK.

Lim, C. S., \& Kor, L. K. (2012). 'Excellent' primary mathematics teachers' espoused and enacted values of effective lessons. ZDM Mathematics Education, 44, 59-69.

Macnab, D. S. (2000). Raising standards in mathematics education: Values, vision and TIMSS. Educational Studies in Mathematics, 42, 61-80.

$\mathrm{Pa}$, N. A. N. (2009). Nilai dan etika dalam pendidikan matematik [Values and ethics in mathematics education]. Kuala Lumpur: Penerbit Universiti Malaya.

Raths, L. E., Harmin, M., \& Simon, S. B. (1987). Selections from values and teaching. In P. F. Carbone (Ed.), Value theory and education (pp. 198-214). Malabar: Krieger.

Seah, W. T. (2002). Exploring teacher clarification of values relating to mathematics education. In C. Vale, J. Roumeliotis, \& J. Horwood (Eds.), Valuing mathematics in society (pp. 93-104). Brunswick: Mathematical Association of Victoria.

Stigler, J. W., \& Hiebert, J. (1999). The teaching gap. New York: Free Press.

Tomlinson, P., \& Quinton, M. (Eds.). (1986). Values across the curriculum. London: Falmer Press.

Yin, R. K. (2003). Case study research: Design and methods (3rd ed.). London: Sage.

Yusof, J., \& Malone, J. (2003). Mathematical errors in fractions: A case of Bruneian primary 5 pupils. In L. Bragg, C. Champbell, G. Herbert, \& J. Mousley (Eds.), Proceedings of the 26th Annual Conference of MERGA (pp. 650-657). 
Open Access This chapter is licensed under the terms of the Creative Commons Attribution 4.0 International License (http://creativecommons.org/licenses/by/4.0/), which permits use, sharing, adaptation, distribution and reproduction in any medium or format, as long as you give appropriate credit to the original author(s) and the source, provide a link to the Creative Commons license and indicate if changes were made.

The images or other third party material in this chapter are included in the chapter's Creative Commons license, unless indicated otherwise in a credit line to the material. If material is not included in the chapter's Creative Commons license and your intended use is not permitted by statutory regulation or exceeds the permitted use, you will need to obtain permission directly from the copyright holder.

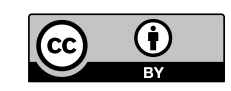

